\title{
GCU
}

Glasgow Caledonian

University

University for the Common Good

\section{Abdominal massage for the alleviation of constipation symptoms in people with multiple sclerosis: a randomized controlled feasibility study}

McClurg, Doreen; Hagen, Suzanne; Hawkins, Stanley; Lowe-Strong, Andrea

Published in:

Multiple Sclerosis Journal

DOI:

$10.1177 / 1352458510384899$

Publication date:

2011

Document Version

Author accepted manuscript

Link to publication in ResearchOnline

Citation for published version (Harvard):

McClurg, D, Hagen, S, Hawkins, S \& Lowe-Strong, A 2011, 'Abdominal massage for the alleviation of constipation symptoms in people with multiple sclerosis: a randomized controlled feasibility study', Multiple Sclerosis Journal, vol. 17, no. 2, pp. 223-233. https://doi.org/10.1177/1352458510384899

\section{General rights}

Copyright and moral rights for the publications made accessible in the public portal are retained by the authors and/or other copyright owners and it is a condition of accessing publications that users recognise and abide by the legal requirements associated with these rights.

Take down policy

If you believe that this document breaches copyright please view our takedown policy at https://edshare.gcu.ac.uk/id/eprint/5179 for details

of how to contact us. 


\section{Title}

Abdominal massage for the alleviation of constipation symptoms in people with multiple sclerosis: a randomised controlled feasibility study

\section{Authors}

McClurg $D^{1}$, Hagen $\mathrm{S}^{1}$, Hawkins $\mathrm{S}^{2}$, Lowe-Strong $\mathrm{A}^{3}$

1 Nursing, Midwifery and Allied Health Professions Research Unit, Glasgow Caledonian University, Glasgow, Scotland

2 Neurology Dept, Queens University, Belfast, Northern Ireland

3 Health and Rehabilitation Sciences Research Institute and School of Health Sciences, University of Ulster, Northern Ireland

\section{Corresponding author}

Dr Doreen McClurg

NMAHP RU

Level 2

Buchanan House

Cowcaddens Rd

Glasgow

G4 0BA

Email Doreen.mcclurg@gcal.ac.uk

Telephone 01413318105

Fax 01413318101

\section{Key words}

Constipation; abdominal massage; multiple sclerosis; faecal incontinence; defaecation; bladder dysfunction

Running title: Abdominal massage for constipation in MS

\section{Acknowledgments}

The authors would like to thank the MS Trust for their financial support, Marian Emly for providing instruction in abdominal massage and use of the supporting DVD, and the participants for their co-operation.

\footnotetext{
Abstract

Constipation affects many people with multiple sclerosis, negatively impacting on their quality of life and well-being. The use of abdominal massage has been reported in several
} 
populations and has been shown to increase the frequency of defaecation without harmful side-effects. Our objective was to undertake a pilot study to determine the feasibility and practicality of undertaking abdominal massage in people with multiple sclerosis (MS).

Following ethical approval 30 patients with MS and constipation were recruited into this single blind randomised controlled trial. After the completion of the consent form and baseline outcome measures participants were randomly allocated to a massage group or a control group. A physiotherapist visited both groups weekly for four weeks. The massage group participants were provided with advice on bowel management and they or their carers were taught how to deliver abdominal massage. It was recommended that the massage was performed daily during the four week intervention period. The control group received bowel management advice only. Outcomes were measured pre (Week 0) and post treatment (Week 4), and at Week 8 and included; The Constipation Scoring System (primary outcome), the Neurogenic Bowel Dysfunction Score and a bowel diary. Both groups demonstrated a decrease in CSS score from week 0 to week 4 indicating an improvement in constipation symptoms, however the massage group improved significantly more than the control groups (mean difference between groups in score change -5.0 (SD 1.5), 95\% CI -8.1, -1.8; $\mathrm{t}=-3.28$, $\mathrm{df}=28, \mathrm{p}=0.003)$.

Questionnaire response rates and compliance with treatment were high.

Data analysis results suggested a potential positive effect of the intervention on the symptoms of constipation and support the feasibility of a substantive trial of abdominal massage for the alleviation of the symptoms of constipation in people with MS.

\section{Introduction}

Bowel dysfunction occurs in $45 \%$ to $69 \%$ of people with MS (Norvedt et al. 2007). However, despite the high prevalence, a Cochrane Review on the 'Management of faecal incontinence and constipation in adults with central neurological diseases' reported there was remarkably little research in this area and concluded that 'no recommendations could be drawn for bowel management which must remain empirical' (Coggrave et al. 2006). Constipation is an unpleasant and often distressing condition, and within the MS population can affect patients at anytime during the disease process (Hinds et al. 1990). Although rarely life threatening, the distress associated with constipation can affect the overall well-being of a patient, with symptom severity correlating negatively with perceived quality of life (Glia and Lindberg 1997). It has also been shown that constipation is a source of considerable psychosocial disability and can influence patients' daily lives to such an extent that they can become totally 
preoccupied with the symptoms (Nortvedt et al. 2007; Friedrichsen and Erichsen 2004; Wiesel et al. 2000; Hinds and Wald 1989). Such symptoms can range from a headache and fatigue to feelings of bloatedness, loss of appetite, nausea, vomiting, overflow incontinence and, concomitantly in the MS patient, exacerbated limb spasticity and bladder dysfunction.

Constipation in people with MS has multiple causes and cannot be linked to a single identifiable neurological deficit (Fowler 1997). Three broad types of constipation have been identified:-

Defaecatory disorders - Pelvic floor muscles may be altered leading to pelvic floor dyssynergia where the external anal sphincter tightens rather than opens during defaecation, which leads to straining and incomplete bowel evacuation (Lembo and Camilleri 2003).

Transit disorders - Abnormalities of colonic activity and a slow transit time have been shown to cause constipation in those with MS (Chia et al. 1995; Weber et al. 1990; Glick et al. 1982). In a study of 6 patients with MS, transit studies revealed 5 had abnormally slow transit with delay being primarily in the distal colon (Waldron et al. 1993). Chia et al. (1996) have speculated that slow transit might be due to an autonomic nervous system deficit such as occurs with a central nervous lesion rostral to the thoracic cord. However, constipation can also occur in patients with little general neurological disability due to MS. An alternative speculative hypothesis is that slow transit is not due to a specific neurological lesion or lesions in the central nervous system, but rather to another mechanism similar to that which causes fatigue in the disease, which is not understood (Fowler 1997).

Other predisposing factors - Constipation may be related to factors such as fibre and fluid intake, mobility, general weakness and fatigue. Medications commonly prescribed to patients with MS, such as muscle relaxants or anticholinergic drugs, are also known to cause constipation (Winge et al. 2003). Finally, psychological factors or behavioural problems may also affect toileting. The end result of such influences is a reduced peristalsis which may exacerbate a slow bowel transit time, resulting in faecal matter that is harder and dryer than normal, causing difficult and often painful defaecation (Winge et al. 2003).

Abdominal massage for the management of constipation was used as early as 1870 , with its use reaching a peak in the late $19^{\text {th }}$ and early $20^{\text {th }}$ century, yet by the 1950 s the therapies had all but disappeared. However, massage has undergone a revival in clinical practice especially within the palliative care, oncology and hospice environments (Trevelyan 1996, Cole and Stanley 1998). Indeed, the MS Trust and the MS Society both advocate its use for the relief of 
constipation (www.mssociety.org.uk; www.mstrust.org.uk) but there is very little research as to its effectiveness. A literature review undertaken in 1999 by Ernst concluded that this intervention should be further investigated through more robust trials. Since 1999 several studies have been undertaken, however none included participants with MS. Preece (2002) reported on a single group study $(n=15)$ within the palliative care setting and concluded that 11 of the patients reported a decrease in the distressing effect of constipation. Jeon and Jung (2005) undertook randomised control trial with 31 patients who had had a CVA comparing a group which had abdominal massage $(n=16)$ to a group who did not, and reported a significant improvement in frequency of defaecation in the massage group compared to the control group. The most recent study, (Lamas et al. 2009) recruited a sample of 60 people with constipation which were randomised to two groups; an intervention group which received the massage and a control group. These authors concluded that the abdominal massage decreased the severity of constipation and increased bowel movements but did not lead to decrease in laxative intake. The present paper describes a pilot study on the efficacy of abdominal massage for the relief of constipation in people with MS.

\section{Methods}

Ethical approval for the study was obtained from the Office for Research Ethics Committees, Northern Ireland (ORECNI: 08/NIRO2/80: 25th September 2008).

Participants and recruitment (See Figure 1)

Following consultation with a statistician it was recommended that we recruit 30 participants in order to adequately test out the trial procedures and provide a robust estimate of the intervention effect size to inform sample size calculations for a definitive randomised controlled trial.

Participants were recruited over a 6 month period. Participants self-referred in response to adverts placed in the Northern Ireland MS Magazine and web-site, and through the PI visiting various MS Groups and day centres to discuss the proposed study.

The project was explained fully to all participants, and an information sheet was provided. The initial screening of individuals included a medical history and a pre-trial questionnaire which recorded participant's age, time since diagnosis, disease course and Expanded Disability Status Scale (EDSS). Included were individuals who were over 18 years of age, had a confirmed diagnosis of MS, fulfilled the Rome II criteria for constipation and were able to understand and agree to the study protocol. Excluded were those with a medical history of Crohn's disease, diverticular disease, colon cancer, rectal bleeding or recent change in bowel function. 


\section{Group allocation}

Written informed consent was obtained from each participant and following completion of baseline outcome measures participants were randomly allocated by the physiotherapist using a web-based system, (http://www.sealedenvelop.com), to Group 1 (massage group) or Group 2 (control group). The individual was informed by telephone and a appointment made for the first physiotherapist visit.

\section{Intervention}

The intervention period was 4 weeks, with participants in both groups receiving weekly visits from the physiotherapist, thus controlling for the potential effects of contact with a clinician. During these visits discussions on the patient's bowel patterns and symptoms were initiated by the physiotherapist and advice was given as necessary regarding good defaecation posture, adequate fluid intake, and the importance of diet and exercise.

In addition, Group 1 participants were instructed, at the first and subsequent visits if necessary, how to carry out abdominal massage by the physiotherapist. The participant was positioned supine with head and shoulders supported and initially the abdomen was assessed for flatus, pain and faecal matter in the gut. The massage began with a gentle relaxing stroke up the abdominal wall. Four basic strokes were then provided - stroking, effleurage, kneading and vibration (see Figure 2). During the visits the patient and carer were instructed in the technique and were given the opportunity to practice and ask questions. A teaching DVD which demonstrated the techniques was also provided.

The abdominal, massage protocol lasted approximately 15 minutes and it was advised that it should be carried out daily by the participant or their carer.

\section{$\underline{\text { Outcome Measurement }}$}

Outcome data were gathered at baseline (Week 0), at the end of the intervention phase (Week 4) and 4 weeks later (Week 8). The questionnaires were administered to participants via telephone by an outcome assessor blinded to group allocation. Participants were also asked to complete a daily bowel diary during the 7 days prior to baseline, during the 4 weeks of intervention, and for 7 days prior to the completion of the week 8 questionnaire.

\section{Primary Outcome Measure}

\section{Constipation Scoring System (CSS: Agachan et al. 1996)}

This is an 8 item questionnaire with items on frequency of bowel movement, difficulty with 
evacuation, feeling of incomplete evacuation, pain, length of time for evacuation, assistance with evacuation (e.g. laxatives), number of failed attempts and the duration of problems with constipation. The maximum score is 30 , with a higher score indicating increased severity.

\section{Secondary Outcome Measures}

Neurogenic Bowel Dysfunction Score (NBDS: Krogh et al. 2005)

This is a 10 item questionnaire covering frequency of bowel movements (0-6 points), headache, perspiration or discomfort before or during defaecation (0-2 points), medication (04 points each), time spent defaecating (0-7 points), frequency of digital stimulation or evacuation (0-6 points), frequency of faecal incontinence (0-13 points), medication to prevent faecal incontinence (0-4 points), flatus incontinence (0-2 points) and perianal skin problems (0-3 points). The maximum score in the NBDS is 47 , the higher the score the more severe the symptoms with a score of 14 or more rated as severe.

\section{Multiple Sclerosis Impact Scale (MSIS-29: Hobart et al. 2001)}

This scale was designed to measure the physical and psychological impact of MS. It is a 29item questionnaire with two subscores measuring Physical (20 items) and Psychological (9 items) impact, with higher scores indicating greater impact.

The Qualiveen Questionnaire (Bonniaud et al. 2005)

This is a 30 item questionnaire assessing bladder related quality of life in neurological patients. Four sub-scales respresenting aspects of patients' lives (bother with limitations, frequency of limitations, fears and feelings) are assessed with response options framed as 5 point scales with 0 indicating no effect and 4 indicating a high adverse effect. Results can be presented by sub-scale and total score. .

Seven Day Bowel Diary

This diary recorded for each of 7 consecutive days:

$\begin{array}{ll}\text { - } & \text { Number of times the participant defaecated each day } \\ \text { - } & \text { How long the person spent trying to defaecate } \\ \text { - } & \text { Number of episodes of faecal incontinence } \\ \text { - } & \text { Feeling of incomplete evacuation } \\ \text { - } & \text { Use of laxatives/enemas } \\ \text { - } & \text { Change in medication, diet and fluid intake }\end{array}$

\section{Analysis}


Data were entered into a study database by a member of the team who was blinded to participants' group allocation. Analysis was undertaken using SPSS Version 17 with group allocation concealed using codes to differentiate between the massage and control arms. Comparison of the baseline characteristics of the two study groups was undertaken using the independent sample t-test or the chi square test. Changes in scores from pre to post intervention (from Week 0 to Week 4 and Week 8) were compared between study groups using the independent sample t-test. The distribution of study variables was assessed for normality to ensure the use of parametric tests was appropriate. A 5\% level of significance was used throughout.

\section{Results}

\section{Baseline characteristics}

Of the first 41 people who expressed an interest in the study 30 individuals (12 male and 18 female) fulfilled the inclusion criteria and were recruited and randomised between March and October 2009 (Figure 1). The mean age of the group was 55 years (SD 13; median 56; range 34-83 years) and mobility (EDSS 2.5) varied from walking unaided (10\%) to wheelchair bound $(40 \%)$. There were no statistically significant differences demonstrated between the groups in any outcome measures at baseline.

\section{$\underline{\text { Recruitment, retention and compliance }}$}

All participants remained in the study up to the end of the intervention period (Week 4); one participant, from the control group, withdrew due to a relapse before the final outcome measures were completed at Week 8.

In terms of compliance with the abdominal massage, all participants in Group 1 received a weekly visit during the intervention period and reported undertaking the massage daily. At Week 8 it was reported by $60 \%$ of participants that they were continuing with the massage.

\section{Primary Outcome Measure}

\section{Constipation Scoring System}

Both groups' CSS scores decreased from Week 0 to Week 4 (Table 2, Figure 1) indicating an improvement in constipation symptoms, however the massage group improved significantly more than the control group (mean difference between groups in score change -5.0 (SD 1.5), 95\% CI -8.1, -1.8; $\mathrm{t}=-3.28, \mathrm{df}=28, \mathrm{p}=0.003)$. There was no difference between groups however in CSS score improvement between Week 0 and Week 8 (mean difference between 
groups in score change $-1.6(\mathrm{SD} 1.5), 95 \% \mathrm{CI}-5.6,0.6 ; \mathrm{t}=-2.64, \mathrm{df}=28, \mathrm{p}=0.112)$.

\section{$\underline{\text { Secondary Outcome Measures }}$}

Neurogenic Bowel Dysfunction Score

The NBD score decreased (improved) in the massage group but increased (worsened) in the control group (Table 3, Figure 2), the difference between groups being statistically significant from Week 0 to Week 8 (mean difference between groups in score change -7.35 (SD 2.4), 95\% CI $-12.45,-2.25 ; \mathrm{t}=-2.95, \mathrm{df}=27, \mathrm{p}=0.006$ ), but not for Week 0 to Week 4 (mean difference between groups in score change -4.4 (SD 2.5), 95\% CI -9.6, 0.68; $\mathrm{t}=-1.77$, df $=28$, $\mathrm{p}=0.086)$.

\section{Bowel Diary}

The frequency of defaecation increased (improved) in both groups but the participants in the massage group improved more than the control group (Table 4, Figure 3), the difference between groups being statistically significant for the change from Week 0 to Week 4 (mean difference between groups in score change -2.2 (SD.58), 95\% CI $-0.98,-0.97 ; \mathrm{t}=3.7, \mathrm{df}=27$, $\mathrm{p}=0.001)$.

There was no significant change in the use of laxatives or stool consistency in either group, however there was a tendency for a reduction in the length of time spent on the toilet in the massage group.

\section{Qualiveen Questionnaire}

There was no significant difference between groups in the Total Qualiveen scores at any time point (mean difference between groups in score change (Week 0 to Week 4) -.11 (SD .16), 95\% CI -.45, .23; t=-.673, df=27, p=.506: (Week 0 to Week 8) .29 (SD .25), CI -.23, .81; $\mathrm{t}=1.169 ; \mathrm{df}=25, \mathrm{p}=.253$ ). According to Bonniaud et al. (2007) the minimal important difference in score to interpret the magnitude of treatment effect is 0.5 in any of the four domains. There was an average change of 0.68 from baseline to Week 4 in the massage group in the 'bother' domain, and similarly an average change of 0.63 from baseline to Week 8 in this domain in the Control Group.

\section{Discussion}


This is the first study which has exclusively involved patients with multiple sclerosis undertaking a programme involving abdominal massage for the relief of constipation. From the findings it would appear that using abdominal massage improves the frequency of defaecation. Furthermore, retention in the massage group was $100 \%$ and there were no adverse incidents reports indicating that it is a feasible intervention for people with MS to undertake and that it is amenable to being evaluated within a randomised controlled trial design.

The causes of constipation are multi-factorial and abdominal massage should be used as part of an integrated bowel management programme. Both groups received the same advice on good defaecation posture, fluid intake, diet and exercise and an improvement in the Constipation Scoring System was evident in all participants. However, those that received the abdominal massage improved significantly more than those that received the advice only on the Constipation Scoring System $(\mathrm{p}=0.00395 \%$ CI $-8.1,-1.8 ; \mathrm{t}=-3.28, \mathrm{df}=28)$ and in the frequency of defaecation ( $\mathrm{p}=0.001,95 \%$ CI $-0.98,-0.97 ; \mathrm{t}=3.7, \mathrm{df}=27)$. Anecdotally participants also found the abdominal relaxing and it was interesting that the majority of participants were keen to undertake the massage themselves as it provided a means of selfhelp and empowerment.

There is debate as to the mechanisms of action of abdominal massage on the bowel, with several possible explanations. It is thought that rectal loading may be encouraged by increasing intra-abdominal pressure, and in some neurological cases it may elicit rectal waves which stimulate the somato-autononic reflex and bowel sensation (Liu et al. 2005). The mechanical and reflex effect on the gut encourages peristalsis enhancing the mass movement of the gut so increasing the strength of the contraction and propulsive force. The function of the gastrointestinal tract is also influenced by activity in the parasympathetic division of the autonomic nervous system. By sensory stimulation of the parasympathetic division there is increased mobility of the muscles of the gut, an increase in the digestive secretions and relaxation of the sphincters in the gastrointestinal canal (Allan 2005; Purves et al. 2007). In one study of preterm neonates massage influenced weight gain (Diego et al. 2007) by increasing vagal activity and gastric motility.

The findings of the current study support work in other patient populations. The most recent of these by Lamas et al. (2009) was a two group randomised study of 60 self-referred patients, who fulfilled the Rome 11 criteria for constipation; the massage group $(n=30)$ received 8 weeks of abdominal massage administered by a clinician, and the control group 
$(n=30)$ received no additional intervention or contact time. Results demonstrated an increase in frequency of defaecation in the massage group, but no change in laxative use. In 2005, a two group RCT comparing abdominal massage $(n=16)$ to no massage $(n=15)$ in patients who had had a cerebro-vascular accident reported significant advantage for the treatment group in terms of increased frequency of defaecation and reduced severity of constipation (Jeon and Jung 2005). Preece (2002) reported some relief of symptoms in the palliative care setting. Patients were taught the technique at the day-care centre and used it at home. However, the study sample size $(n=15)$ was small and there was no control group. Anecdotal evidence and expert opinion also suggests abdominal massage to be an effective treatment option for the management of constipation, with the added advantage that it is perceived by patients to be relaxing and provides relief from 'trapped wind' (Longworth 1982, Ferrell-Torry \& Glick 1993, Fraser \& Ross-Kerr 1993, Stevenson 1994). Yet rigorous evidence of the effectiveness and cost-effectiveness of abdominal massage for the management of constipation is still lacking, despite The Royal College of Physicians suggesting some years ago that randomised controlled trials were needed to address this evidence gap (Potter et al. 2002). The results of the current study add to the available evidence and, following the MRC guidance on developing and evaluating complex interventions (MRC 2000), equip us with the information needed to undertake a multi-centre RCT adequately powered to detect differences across a range of outcomes which are important to patients with MS.

It was interesting that many of the participants found the Bowel Diary a useful tool both for monitoring frequency of defaecation and as an aid to remember to take their laxative medication. Some also said it was useful as the Bristol Stool Chart gave them the language to use when discussing their constipation with clinicians. Most participants also found the DVD demonstrating the massage was very useful, although one participant with partial sight had difficulty seeing it.

All Outcome Measures, except for the Bowel Diary, were completed by telephone administration. This was felt an appropriate method for this particular group of patients because of the potential problems with eye-sight and although it could be time consuming for the RA it facilitated $100 \%$ completion.

There are several limitations to this study. Results should be interpreted with caution due to the small sample size which reflects the feasibility nature of the study. Patients self-referred to the study and were therefore potentially more motivated than the general MS population, and due to the nature of the intervention it was not possible to blind the patient or clinician. Abdominal massage also requires a period of time to influence constipation. In the present 
study the duration of the massage (4 weeks) was quite short compared to other studies, for example Lamas et al (2009) only found significant differences at week 8, and it may be the effect would have continued to increase if the duration of intervention had been longer. Furthermore, some participants felt that in applying the massage technique themselves they were unable to exert the same pressure achieved by the physiotherapist and also could be quite fatiguing. This could reduce the potential effect of the intervention (Lamas et al 2009). Although the results of this trial cannot definitively recommend the use of abdominal massage it would appear that with adequate training provided to the clinician, patient or carer it is has potential in a programme of treatment to help alleviate constipation in people with MS

\section{Conclusion}

This paper describes a feasibility study of the effectiveness of abdominal massage in relieving constipation in people with MS. Questionnaire response rates and compliance with treatment were high and data analysis results indicated a potential positive effect of the intervention on the symptoms of constipation. Further research is now warranted in the form of a multi-centre randomised controlled clinical trial with an adequately powered sample size. 
Figure 1 Recruitment and Progress or participants through study

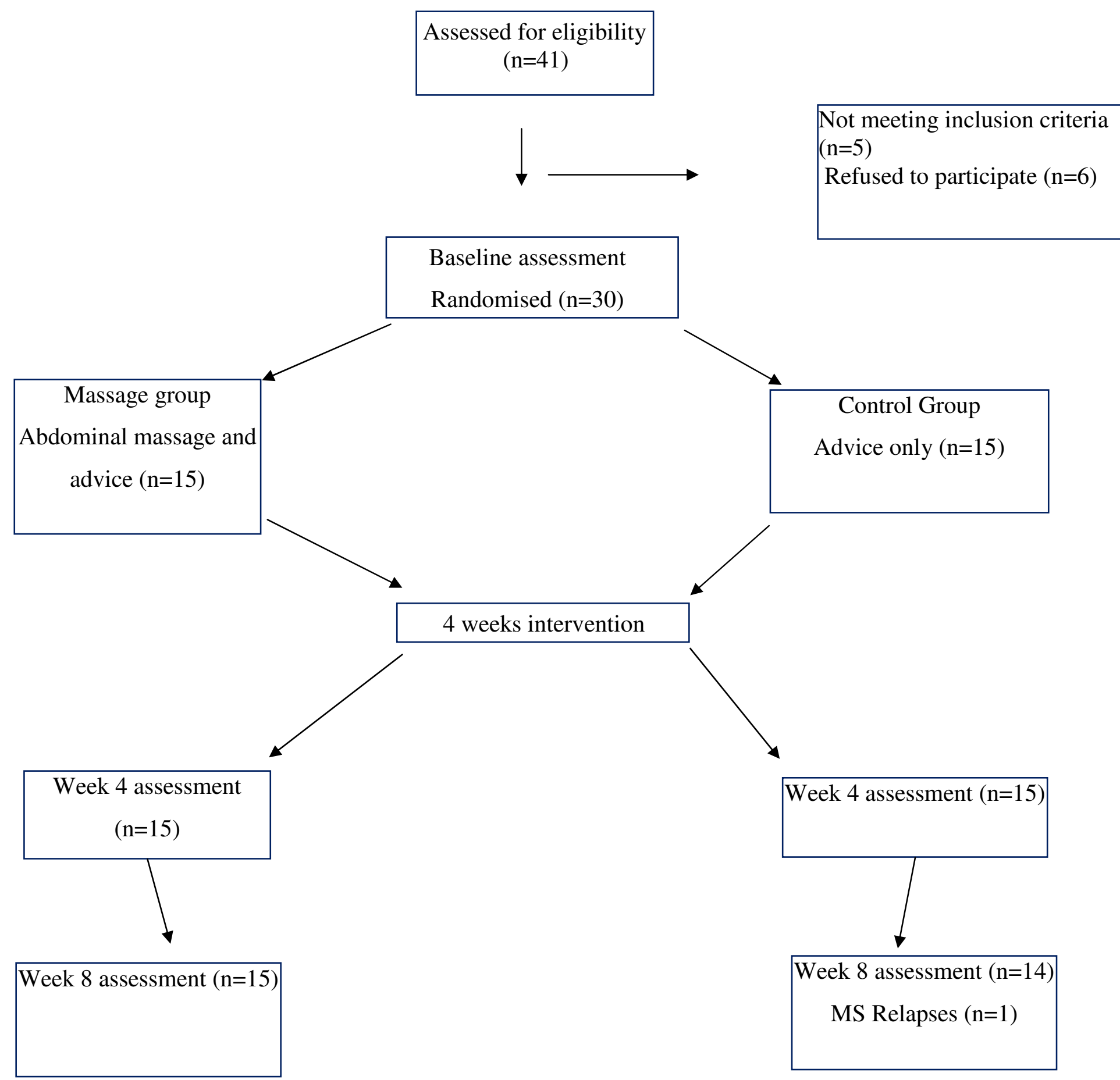




\section{Figure 2 Massage Technique}

Stroking commenced from the small of the back and followed the dermatome of the vagus nerve, over the iliac crests, and down both sides of the pelvis towards the groin. This was repeated several times.

Effleurage strokes followed the direction of the ascending colon across the transverse colon and down the descending colon. This was repeated several times with increased pressure to stimulate the austral and segmental contractions of the large intestine with the aim of propelling the faecal matter along the gut.

Palmar Kneading is the heart of the massage and tracks down the descending colon, up the ascending colon, and down the descending colon once again. Kneading assists in propelling the faecal matter along the gut to load the rectum. Finger kneading may be required to break up faecal mass. This part of the massage may sometimes be uncomfortable because of the deep compression required.

Effleurage was repeated and continued with a relaxing transverse stroke over the abdomen.

Vibration over the abdominal wall to relieve flatus concluded the massage session. 
Table 1 Demographic Characteristics

$\begin{array}{rrr}\text { Group 1 } & \text { Group 2 } & p \text { value } \\ \text { Treatment } & \text { Control } & \text { (Independent } \\ & \text { sample t-test, Chi } \\ & \text { square test) }\end{array}$

Gender

5 male, 10 female

7 male, 8 female

0.36

Age range (years),

52.4

(34-83)

0.16

mean (years)

12.32

59.3

SD

14.7

\section{Type of MS}

Secondary Progressive

Relapsing remitting

Primary progressive

Benign

6

1

0

0.19

EDSS:mean (SD)

$2(1) 1-5$

$3(1) 1-6$

0.42

range

14

13

Bladder Problem

Intermittent self catheterisation

7

3

0.13

Indwelling Catheter

2

7

0.10

\section{Laxative use}

No laxatives

Movicol

Lactulose

Other

$\begin{array}{ll}6 & 6 \\ 4 & 8 \\ 3 & 1 \\ 2 & 0\end{array}$


Table 2 Change in Constipation Scoring System (CSS)

\begin{tabular}{|l|l|r|r|r|r|}
\hline Change & Group & $\mathrm{n}$ & $\begin{array}{r}\text { Mean } \\
\text { difference }\end{array}$ & $\mathrm{SD}$ & $\begin{array}{r}\text { Independent } \\
\text { sample t-test } \\
p \text { value }\end{array}$ \\
\hline Baseline - Week 4 & $\begin{array}{l}\text { Gp 1 } \\
\text { Intervention }\end{array}$ & 15 & -5.6667 & 4.5 & 0.003 \\
\cline { 2 - 6 } & Gp 2 Control & 15 & -.6667 & 3.7 & 0.112 \\
\hline Baseline - Week 8 & $\begin{array}{l}\text { Gp 1 } \\
\text { Intervention }\end{array}$ & 15 & -3.6000 & 4.0 & \\
\hline & Gp2 Control & 14 & -1.0714 & 4.25 & \\
\hline
\end{tabular}

\section{Figure 1 Line Graph showing change in CSS}

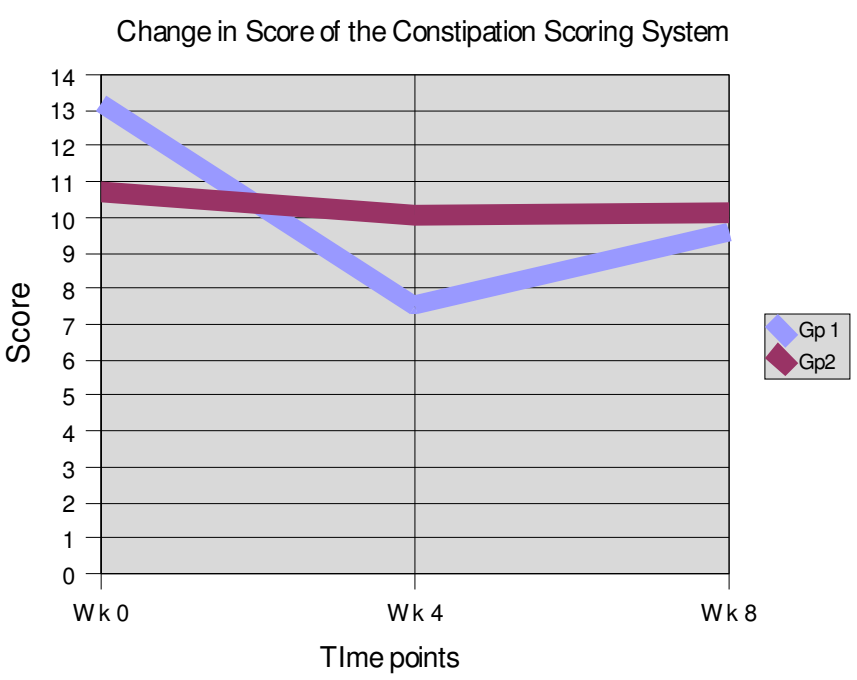

Group 1 Massage; Group 2 Control 
Table 3 Change in Neurogenic Bowel Score (NBS)

\begin{tabular}{|l|l|l|r|r|r|}
\hline Change & Group & $\mathrm{n}$ & $\begin{array}{l}\text { Mean } \\
\text { difference }\end{array}$ & \multicolumn{1}{|l|}{$\begin{array}{r}\text { Independent } \\
\text { sample y-Test } \\
p \text { value }\end{array}$} \\
\hline Baseline - Week 4 & $\begin{array}{l}\text { Gp 1 } \\
\text { Intervention }\end{array}$ & 15 & -4.2667 & 7.8 & 0.086 \\
\cline { 2 - 6 } & Gp 2 Control & 15 & .2000 & 5.8 & 0.006 \\
\hline Baseline - Week 8 & $\begin{array}{l}\text { Gp 1 } \\
\text { Intervention }\end{array}$ & 15 & -5.0000 & 6.1 & \\
\hline & Gp 2 Control & 14 & 2.35711 & 7.2 & \\
\hline
\end{tabular}

Figure 2 Line graph showing change in NBS

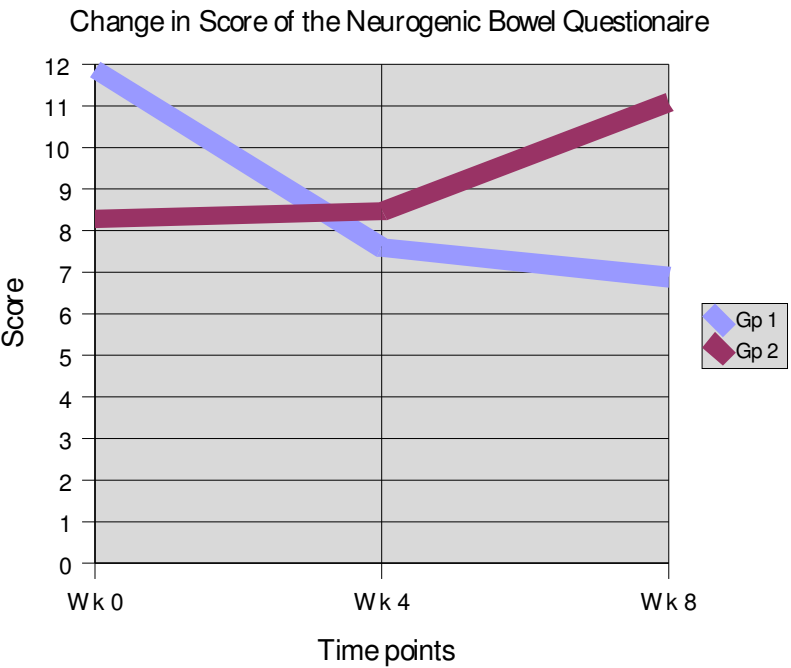

Group 1 Massage; Group 2 Control 
Table 4 Change in Frequency of Defaecation

\begin{tabular}{|l|l|l|r|r|r|}
\hline Change & Group & $\mathrm{n}$ & $\begin{array}{r}\text { Mean } \\
\text { difference }\end{array}$ & SD & $\begin{array}{r}\text { Independent } \\
\text { sample t-Test } \\
p \text { value }\end{array}$ \\
\hline Baseline - Week 4 & $\begin{array}{l}\text { Gp 1 } \\
\text { Intervention }\end{array}$ & 15 & 1.7333 & .37 & .001 \\
\cline { 2 - 5 } & $\begin{array}{l}\text { Gp 2 } \\
\text { Control }\end{array}$ & 15 & -.4286 & .44 & \\
\hline
\end{tabular}

Figure 3 Frequency of Defaecation

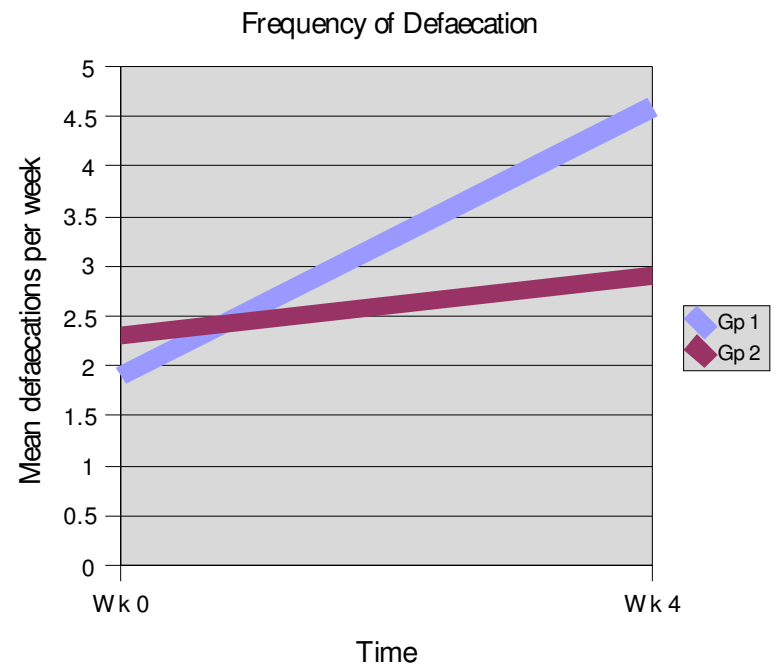

Group 1 Massage; Group 2 Control 



\section{References}

Agachan F, Chen T, Pfiefer J et al. (1996). A constipation scoring system to simplify evaluation and management of constipated patients. Diseases of the Colon and Rectum. 39(6):681-685

Allan, D., 2005. The central nervous system. In: Montague, S.E., Watson,R., Herbert, R.A. (Eds.), Physiology for Nursing Practice. Elsevier, Philadelphia.

Bonniaud V, Jackowski D, Parratte B, Paulseth R, Grad S, Margetts, P Guyatt G. (2005). Quality of life in multiple sclerosis patients with urinary disorders; discriminative validation of the English version of Qualiveen. Qual Life Res. 14(2):425-431

Bonniaud V, Bryant D, Parratte B, Guyatt G. (2008). Qualiveen a urinary disorder specific instrument: 0.5 corresponds to the minimal important difference. J Clin Epidemiol 61(5):505-10

Chia YW, Fowler C, Kamm M et al. (1995). Prevalence of bowel dysfunction in patients with multiple sclerosis and bladder dysfunction. Journal of Neurology. 242:105-108.

Chia YQ, Gill KP, Jameson JS, et al. (1996). Paradoxical puborectalis contraction is a feature of constipation in patients with multiple sclerosis. J Neurol Neurosurg Psychiatry. 60:31-35.

Coggrave M, Wiesel PH, Norton C. (2006). Management of faecal incontinence and constipation in adults with central neurological diseases. Cochrane Database Systematic Review CD002115.

Cole A. and Stanley E (1998). Complementary therapies as a means of developing the scope of professional nursing practice. Journal of Advanced Nursing. 27:1171-1176

Craig et al. (2008) Developing and evaluating complex interventions: the new MRC guidance. BMJ. 337:979-983

Diego M.A, Field, T, Hernandez-Reif M, Deeds O, Ascencio A, Begert G. (2007). Preterm infant massage elicits consistent increases in vagal activity and gastric motility that are associated with greater weight gain. Acta Paediatrica 96 (11):1588-1591.

Ernst E. (1999). Abdominal massage therapy for chronic constipation: A systematic review of controlled trials. Forsch Komplementarmed. 6(3):149-151

Ferrell-Torry A.T. \& Glick O.J. (1993) The use of therapeutic massage as a nursing intervention to modify anxiety and the perception of cancer pain. Cancer Nursing. 16(2):93101

Fowler C. (1997). The cause and management of bladder, sexual and bowel symptoms in multiple sclerosis. Balliere's Clinical Neurology. 6(3):447-466.

Fraser J, and Ross-Kerr J. (1993) Psychophysiological effects of back massage in elderly institutionalised patients. Journal of Advanced Nursing. 18:238-245.

Friedrichsen M, and Erichsen E. (2004). The lived experience of constipation in cancer patients in palliative hospital-based home care. International Journal of Palliative Nursing. 10(7):321-325.

Glia A, and Lindberg G. (1997). Quality of life in patients with different types of functional constipation. Scandinavian Journal of Gastroenterology. 32(11):1083-1089

Glick E, Meshkinpur H, Haldeman S, et al. (1982). Colonic dysfunction in multiple sclerosis 
Gastroenterology. 83:1002-1007.

Hinds JP, Eidelman BH, Wald A. (1990). Prevalence of bowel dysfunction in multiple sclerosis. Gastroenterology 98:1538-42.

Hinds JP, Wald A. (1989). Colonic and anorectal dysfunction associated with multiple sclerosis. Am J Gastroenterol. 84(6):587-95

Hobart J, Lamping DL, Fitzpatrick, Riazi A, Thompson A. (2001). The Multiple Sclerosis Impact Scale (MSIS-29); a new patient-based outcome measure. Brain. 124:962-973.

Jeon SY, Jung HM. (2005). The effects of abdominal meridian massage on constipation among CVA patients. Daehan Ganho Haghoeju. 35(1):135-142.

Krogh K, Christensen P, Sabore S, Laurberg A. (2006). Neurogenic Bowel Dysfunction Score. Spinal Cord. 44(10):625-631.

Lembo A, Camillerai M. Current concepts: chronic constipation. (2003). N Engl J Med. 349:13601368

Lamas K, Lindholm L, Stenlund L, Stenlund H, Engstrom B, Jacobsson C. (2009). Effects of abdominal massage in management of constipation-A randomized controlled trial International Journal of Nursing Studies 46:759-767

Liu Z, Sakakibara R, Odaka T, Uchiyama T, Yamamoto T, Ito T, Hattori, T. (2005). Mechanism of abdominal massage for difficult defecation in a patient with myelopathy (HAM/TSP). Journal of Neurology 252 (10), 1280-1282.

Longworth J. (1982) Psychophysiological effects of slow stroke back massage in normotensive females. Advances in Nursing Science. 44-60.

Medical Research Council. A framework for the development and evaluation of RCTs for complex interventions to improve health. London: MRC, 2000.

www.mssociety.org.uk; Patient information leaflet accessed 'Bowel and Bladder Problems' accessed May 2008

www.mstrust.org.uk; Patient information leaflet 'Bowel problems in MS' accessed May 2008

Nortvedt MW, Riise T, Frugard J, Mohn J, Bakke A, Myhr AB and KM. (2007). Prevalence of bladder, bowel and sexual problems among multiple sclerosis patients two to five years after diagnosis. Multiple Sclerosis. 13:106-112.

Potter J, Norton C, Cottenden A. (2002) Bowel Care in Older People. Royal College of Physicians, London

Preece J. 2002. Introducing abdominal massage in palliative care for the relief of constipation. Complementary Therapies in Nursing \& Midwifery 8:101-105.

Purves D, Augustine G.J, Fitzpatrick D, Hall WC, LaMantia, AS,McNamara, JO, White, LE. (2007) Neuroscience. Sinauer Associates, Inc., Massachusetts. 
Stevenson C.J. (1994) The Psychophysiological effects of aromatherapy massage following cardiac surgery. Complementary Therapy Medicine. 2:27-35

Trevelyan J (1996) A true complement? Nursing Times. 92(5):42-43.

Waldron DJ, Horgan PG, Patel FR, et al. (1993) Multiple sclerosis: assessment of colonic and anorectal function in the presence of faecal incontinence. Int J Colorectal Dis. 8:220-224.

Watanabe T, Nakaya N, Kurahima K, et al. (2004) Constipation laxative use and risk of colorectal cancer: the Miyagi cohort study. Eur J Cancer. 40:2109-2115.

Weber J, Delanger T, Hannequin D et al. (1990) Anorectal manometric anomalies in seven patients with frontal lobe brain damage. Digestive Diseases and Sciences. 35:225-230.

Wiesel PH, Norton C, Roy A, Storrie J, Bowers J, Kamm. M. (2000). Gut focused behavioural treatment (biofeedback) for constipation and faecal incontinence in multiple sclerosis. $J$ Neurol Neurosurg Psychiatry. 69:240-243.

Winge K, Rasmusssen D, Werdelin L. (2003). Constipation in neurological diseases. J Neurol Neurosurg Psychiatry. 74:13-19. 